\title{
Pesquisa de anticorpos anti-Leptospira spp. em grupos ocupacionais no Estado de Pernambuco
}

\author{
Detection of antibodies to Leptospira spp. in serum samples from occupational \\ groups in the State of Pernambuco
}

RIALA6/1612

Gesika Maria da SILVA ${ }^{1 *}$, Júnior Mário Baltazar de OLIVEIRA², Adalberto Leite SILVA NETO², Nivaldo Aparecido de ASSIS $^{3}$, Luis Antonio MATHIAS ${ }^{3}$, Daniel Friguglietti BRANDESPIM ${ }^{2}$, José Wilton PINHEIRO JÚNIOR²

*Endereço para correspondência: ${ }^{1}$ Programa de Pós-Graduação em Ciência Animal Tropical, Universidade Federal Rural de Pernambuco. Rua Dom Manoel de Medeiros, s/n, Dois Irmãos, Recife, Brasil. CEP: 52171-900. Tel: (81) 3320-6103. E-mail: gesika.silva@yahoo.com.br

${ }^{2}$ Unidade Acadêmica de Garanhuns, Universidade Federal Rural de Pernambuco

${ }^{3}$ Laboratório de Diagnóstico de Brucelose e Leptospirose, Departamento de Medicina Veterinária Preventiva e Reprodução Animal, Faculdade de Ciências Agrárias, UNESP Jaboticabal

Recebido: 13.08.2014 - Aceito para publicação: 22.09.2014

\section{RESUMO}

A prevalência de anticorpos anti-Leptospira spp. foi determinada em grupos ocupacionais do município de Garanhuns no Estado de Pernambuco, Brasil. Foram colhidas 154 amostras, e um questionário foi aplicado para a análise dos fatores de risco. O diagnóstico sorológico foi realizado utilizando-se a técnica de soroaglutinação microscópica (SAM). A prevalência de anticorpos anti-Leptospira spp. foi de 5,19\% (8/154; I.C. 2,27 \% - 9,98 \%); os participantes da zona urbana apresentaram prevalência de 5,68 \% (5/88; I.C. $1,87 \%$ - 12,76 \%) e os da zona rural de 4,55 \% (3/66; I.C. 0,95 \% - 12,71\%). Os sorovares mais frequentes foram Grippotyphosa (12,5\%) na área rural, na área urbana Autumnalis (12,5\%), enquanto Wolffi (25\%) e Australis (50\%) foram verificados na área rural e na urbana. Na análise de fatores de risco não foi observada associação entre as variáveis estudadas e a reatividade na sorologia. Este foi o primeiro estudo a relatar a presença de anticorpos anti-Leptospira spp. em trabalhadores urbanos e rurais do município de Garanhuns. Este achado alerta para a atenção e realização de pesquisas em áreas de baixa prevalência ou silenciosas para leptospirose, pois desta forma medidas de controle e prevenção poderão ser implementadas.

Palavras-chave. epidemiologia, leptospirose, saúde pública.

\begin{abstract}
This study aimed at determining the prevalence of anti-Leptospira spp. antibodies in occupational groups in the municipality of Garanhuns - State of Pernambuco, Brazil. One hundred fifty-five samples were collected, and a questionnaire for analyzing risk factors was applied. The serological diagnosis was performed by using Microscopic Agglutination Test (MAT). The prevalence of anti-Leptospira spp. was $5.19 \%(8 / 154$, CI $2.27 \%-9.98 \%)$. Among the participants from urban areas the prevalence was 5.68 $\%(5 / 88$, CI $1.87 \%-12.76 \%)$, and $4.55 \%$ in rural areas (3/66, CI $0.95 \%-12.71 \%)$. The most common serotypes were Grippotyphosa (12.5\%) in rural areas, and in the urban area was Autumnalis (12.5\%); Wolffi (25\%) and Australis (50\%) were observed both in rural and urban areas. In analyzing the risk factors, no association was observed between variables and serology reactivity. This study has been the first report on the detection of anti-Leptospira spp. antibodies in urban and rural workers of the municipality of Garanhuns. This finding points out the care and the performance of studies in areas of low or silent prevalence for leptospirosis, for implementing prevention and control measures.
\end{abstract}

Keywords. epidemiology, leptospirosis, public health. 


\section{INTRODUÇÃO}

A leptospirose é uma antropozoonose, causada por bactérias do gênero Leptospira que pode provocar uma doença infecciosa febril de início abrupto, apresentando um amplo espectro de manifestação da doença, de infecções inaparentes à evolução para quadros clínicos de alta gravidade que podem levar à morte ${ }^{1}$.

O gênero Leptospira possui 14 espécies patogênicas e mais de 260 sorovares já foram identificados ${ }^{2}$. As diferentes espécies de roedores podem ser reservatórios de sorovares distintos ${ }^{3}$. Os homens são hospedeiros acidentais, infectam-se de maneira direta quando entram em contato com urina do reservatório contaminada, ou indiretamente por meio do contato com água, solo lamacento ou alimentos contaminados ${ }^{4}$.

Estudos de prevalência são realizados para investigação da infecção em diferentes partes do mundo, como o realizado no nordeste do Irã, com uma prevalência de anticorpos anti-Leptospira de 15,79\% (45/285), para os sorovares Icterohaemorrhagiae, Hardjo, Grippotyphosa, Pomona, Canicola e Ballum ${ }^{5}$. No estado de Veracruz, no México, foi observada uma prevalência de anticorpos anti-Leptospira de 6,4\% $(11 / 171)^{6}$. Na cidade de Pereira, na Colombia, foi detectada uma prevalência de $25 \%$ (5/20) em funcionários de um zoológico e os sorovares mais frequentes foram Bataviae, Grippotyphosa, Hurstbridge ${ }^{7}$.

No Brasil, alguns estudos sorológicos foram realizados para determinar a prevalência da infecção por Leptospira spp. em humanos e observou-se uma variação de $1,3 \%$ a $25 \%^{8-14}$.

Em relação aos fatores de risco, estudo aponta que êxodo rural e a ocupação desordenada das cidades, principalmente em lugares próximos a córregos e riachos, além da falta de organização das redes de saneamento básico, aliados à grande aglomeração populacional de baixa renda e infestações por roedores favoreceram o aumento na incidência de casos de leptospirose no meio urbano e peri-urbano ${ }^{15}$.

Considerando a importância e o risco ocupacional relacionado a essa enfermidade, objetivou-se com este estudo determinar a soroprevalência e fatores de risco associados à infecção por Leptospira spp. em profissionais responsáveis pela limpeza urbana, catadores de material reciclável e trabalhadores rurais do município de Garanhuns, Estado de Pernambuco, Brasil.

\section{MATERIAL E MÉTODOS}

$\mathrm{O}$ projeto foi submetido à apreciação e aprovado pelo Comitê de Ética em Pesquisa (CEP) da Universidade de Pernambuco (PROPEGE/UPE) por meio da Plataforma Brasil, com número CAAE 03798812.3.0000.5207, com o parecer número 79157.

Para realização deste estudo, utilizou-se uma análise epidemiológica transversal com profissionais que atuavam no município de Garanhuns/PE, localizado no Planalto da Borborema, a $230 \mathrm{Km}$ da capital do Estado, Recife. Para determinar o tamanho da amostra utilizouse uma prevalência esperada para infecção por Leptospira spp. de $10,4 \%{ }^{9}$, o que determinou um tamanho mínimo de 110 indivíduos, considerando o nível de confiança de $95 \%$ e erro estatístico de $5 \%{ }^{16}$. Como margem de segurança, foram colhidas 154 amostras de profissionais que atuam na zona urbana e rural, sendo 95 do sexo masculino e 59 do sexo feminino, nos meses de agosto e setembro de 2012. Na zona urbana, foram selecionadas uma empresa terceirizada de limpeza urbana $(n=80)$ e uma associação de catadores de material para reciclagem $(\mathrm{n}=8)$. Na zona rural, foram amostrados 66 trabalhadores rurais cadastrados no Posto de Saúde da Família (PSF) localizado no distrito de São Pedro, pertencente ao município de Garanhuns.

Não houve critérios de inclusão ou exclusão, os voluntários foram convidados a participar da pesquisa com antecedência, por demanda espontânea e nos dias agendados foram obtidas as amostras. Antes da colheita das amostras, foi esclarecido sobre os objetivos da pesquisa e, os que concordaram em participar assinaram e receberam uma via do TCLE - Termo de Consentimento Livre Esclarecido, conforme Resolução $n^{\circ} 466 / 12$ do Conselho Nacional de Saúde ${ }^{17}$. Foi aplicado um questionário com questões objetivas que incluía informações demográficas (sexo, idade, endereço, ocupação e tempo exercendo essa atividade) e perguntas relacionadas aos fatores de risco para a ocorrência da infecção (presença de roedores em casa ou no trabalho, destino do lixo, acúmulo de lixo próximo a casa). Foram colhidas amostras com aproximadamente $10 \mathrm{~mL}$ de sangue, com seringa e agulha descartáveis. Os tubos identificados posteriormente foram centrifugados a 5000 rpm por 10 minutos, e as alíquotas de soro em microtubos de polipropileno foram armazenadas a $-20^{\circ} \mathrm{C}$ na Central de Laboratórios de Garanhuns da Unidade Acadêmica de 
Garanhuns - CENLAG, até a realização da sorologia.

Para o diagnóstico sorológico empregou-se a técnica de Soroaglutinação Microscópica $(\mathrm{SAM})^{18}$, na qual utilizaram-se como antígenos 24 sorovares de Leptospira interrogans vivas cultivadas em meio EMJH (Ellinghausen-McCullough-Johnson-Harris), livres de contaminação e auto-aglutinação, sendo eles: Andamana, Australis, Autumnalis, Bataviae, Bratislava, Butembo, Canicola, Castellonis, Copenhageni, Cynopteri, Hardjo, Hebdomadis, Grippotyphosa, Icterohaemorrhagiae, Javanica, Panama, Pomona, Patoc, Pyrogenes, Sentot, Shermani, Tarassovi, Whitcombi e Wolffi ${ }^{19}$. Foram considerados positivos os soros que apresentaram aglutinação de pelo menos $50 \%$ das Leptospiras no campo microscópico a partir da diluição $1: 100^{14}$. Os reagentes na triagem (1:50) foram submetidos a diluições seriadas a partir de 1:100, sendo considerado o maior título o último em que ainda foi observada aglutinação em mais de $50 \%$ do campo escuro.

Realizou-se a análise estatística descritiva para cálculos das frequências relativa e absoluta dos resultados obtidos no teste sorológico. Para identificar a associação entre as variáveis epidemiológicas e o resultado do exame sorológico, aplicou-se análise univariada das variáveis de interesse pelo teste Exato de Fisher e foram submetidas a uma análise multivariada pelo modelo regressão logística. Para análise dos dados utilizou-se o software Epi Info, versão 7.1.1.0 - Centers for Disease Control and Prevention (CDC).

\section{RESULTADOS}

A prevalência geral de anticorpos anti-Leptospira spp. foi de $5,19 \%(8 / 154$; I.C. $2,27 \%$ - 9,98 \%), na área urbana a prevalência foi de 5,68 \% (5/88; I.C. $1,87 \%$ $12,76 \%)$ e na área rural foi de $4,55 \%$ (3/66; I.C. $0,95 \%$ $-12,71 \%)$.

Observou-se que a prevalência em relação ao sexo foi de $6,17 \%(5 / 81)$ em trabalhadores do sexo masculino na área urbana e $14,29 \%(2 / 14)$ na área rural. Para o sexo feminino observou-se prevalência de $1,82 \%$ (1/52) na área rural e nenhum reagente na área urbana.

A frequência dos sorovares para Leptospira spp. e a distribuição por área urbana e rural estão descritas na Tabela 1.

Tabela 1. Distribuição da frequência dos sorovares das amostras reagentes dos trabalhadores urbanos e rurais do município de Garanhuns, Pernambuco

\begin{tabular}{|c|c|c|c|c|c|c|}
\hline \multirow{3}{*}{ Sorovar } & \multicolumn{6}{|c|}{ Titulação } \\
\hline & \multicolumn{2}{|c|}{100} & \multicolumn{2}{|c|}{200} & \multicolumn{2}{|c|}{400} \\
\hline & Urbana & Rural & Urbana & Rural & Urbana & Rural \\
\hline Autumnalis & 1 & - & - & - & - & - \\
\hline Wolffi & - & 1 & 1 & - & - & - \\
\hline Total & 3 & 2 & 1 & 1 & 1 & - \\
\hline
\end{tabular}

A análise de associação entre as variáveis epidemiológicas e a sorologia para pesquisa de anticorpos anti-Leptospira spp. dos participantes da zona urbana encontra-se disposta na Tabela 2. Na área rural não foi identificada associação entre as variáveis analisadas: acúmulo de lixo próximo a casa $(\mathrm{p}=1,000)$ e depósito de armazenamento de grãos $(0,457)$.

$\mathrm{Na}$ regressão logística não foi identificada associação entre as variáveis analisadas para as áreas urbana e rural e infecção por Leptospira spp. 
Silva GM, Oliveira JMB, Silva Neto AL, Assis NA, Mathias LA, Brandespim DF, et al. Pesquisa de anticorpos anti-Leptospira spp. em grupos ocupacionais no Estado de Pernambuco. Rev Inst Adolfo Lutz. São Paulo, 2014; 73(2):252-9.

Tabela 2. Análise dos fatores de risco associados à infecção por Leptospira spp. em profissionais responsáveis pela limpeza urbana, coleta de material para reciclagem do município de Garanhuns do Estado de Pernambuco, Brasil

\begin{tabular}{|c|c|c|c|c|}
\hline \multirow[t]{2}{*}{ VARIÁVEL } & \multirow[t]{2}{*}{$\mathbf{N}$} & SOROLOGIA & $\begin{array}{c}\text { ANÁLISE } \\
\text { UNIVARIADA } \\
\end{array}$ & \multirow[t]{2}{*}{$\mathbf{P}$} \\
\hline & & Reagente & OR (I.C. $95 \%)$ & \\
\hline \multicolumn{5}{|l|}{ Tempo da ocupação } \\
\hline Menos que 5 anos & 60 & $4(6,6 \%)$ & \multirow{2}{*}{$1,92(0,20-18,09)$} & \multirow{2}{*}{1,0000} \\
\hline Mais que 5 anos & 28 & $1(3,5 \%)$ & & \\
\hline \multicolumn{5}{|l|}{ Qual o horário de trabalho? } \\
\hline Diurno & 61 & $2(3,2 \%)$ & - & \multirow{3}{*}{0,0233} \\
\hline Noturno & 7 & $2(28,5 \%)$ & $11,80(1,35-102,54)$ & \\
\hline Ambos & 20 & $1(5,0 \%)$ & $1,55(0,13-18,09)$ & \\
\hline \multicolumn{5}{|c|}{ Trabalha em terrenos baldios? ${ }^{1}$} \\
\hline Sim & 62 & $2(3,2 \%)$ & \multirow{2}{*}{$0,23(0,03-1,49)$} & \multirow{2}{*}{0,1300} \\
\hline Não & 24 & $3(12,5 \%)$ & & \\
\hline \multicolumn{5}{|c|}{ Trabalha em áreas de esgoto a céu aberto ${ }^{1}$} \\
\hline Sim & 67 & $3(4,4 \%)$ & \multirow{2}{*}{$0,32(0,05-2,15)$} & \multirow{2}{*}{0,2449} \\
\hline Não & 16 & $2(12,5 \%)$ & & \\
\hline
\end{tabular}

Trabalha em lugares como valas, galerias e esgotos? ${ }^{1}$

\begin{tabular}{|c|c|c|c|c|}
\hline Sim & 38 & $1(2,6 \%)$ & \multirow{2}{*}{$0,29(0,03-2,77)$} & \\
\hline Não & 48 & $4(8,3 \%)$ & & \\
\hline
\end{tabular}

Observa roedor no local de trabalho? ${ }^{2}$

$\begin{array}{lll}\text { Sim } & 66 & 2(3,0 \%) \\ \text { Não } & 21 & 3(14,2 \%)\end{array}$

$0,18(0,03-1,21)$

0,0884

Utiliza proteção no trabalho? ${ }^{3}$

$\begin{array}{lll}\text { Sim } & 75 & 4(5,3 \%) \\ \text { Não } & 10 & 1(10,0 \%)\end{array}$

$0,50(0,50-5,04)$

0,4738

Participou de treinamento para iniciar no trabalho? ${ }^{2}$

$\begin{array}{lll}\text { Sim } & 21 & 1(4,76 \%) \\ \text { Não } & 66 & 4(6,06 \%)\end{array}$

$0,77(0,08-7,34)$

1,0000

Qual a fonte de fornecimento de água na residência?

$\begin{array}{ccc}\text { Água encanada } & 81 & 3(3,7 \%) \\ \text { Outras } & 7 & 2(28,57 \%)\end{array}$

$0,09(0,01-0,71)$

$0,0487^{*}$

A casa alaga quando chove?

$\begin{array}{ccc}\text { Sim } & 8 & 1(12,5 \%) \\ \text { Não } & 80 & 4(5,0 \%)\end{array}$

$2,71(0,26-27,73)$

0,3863

N - Total de amostras; OR - Odds Ratio (Razão de Chance); IC - Intervalo de Confiança; ${ }^{\star}$ Associação significativa $(\mathrm{P}<0,05) ;{ }^{1}$ Base utilizada $(86) ;{ }^{2}$ Base utilizada (87); ${ }^{3}$ Base utilizada (85) 


\section{DISCUSSÃO}

A baixa prevalência encontrada neste estudo confere com os dados registrados no Sistema de Informação de Agravos de Notificação (SINAN), no qual onde se constatou a ocorrência de três casos de leptospirose no município de Garanhuns/PE, no período de 2007 a 2012.

Ao analisar os sorovares, observou-se neste estudo a ocorrência de Australis, Autumnalis, Grippotyphosa e Wolffi. De modo semelhante, outros autores também relataram os sorovares Autumnalis ${ }^{12}$, Australis ${ }^{9}$, Grippotyphosa ${ }^{5,7}$ e Wolffi ${ }^{10}$ como os mais prevalentes.

O sorovar mais prevalente neste estudo foi Australis. Este sorovar é relatado na literatura como responsável pela infecção em ovinos ${ }^{20,21}$, sendo estes uma possível fonte de infecção para os reagentes nesta pesquisa, visto que é comum na periferia da cidade a criação de animais de produção. O sorovar Autumnalis é descrito em estudos de prevalência em cães ${ }^{22,23}$, bovinos ${ }^{24}$ e ovinos ${ }^{20,21,25}$. Enquanto que soravar Grippotyphosa é comumente associado a marsupiais ${ }^{26,27}$. Observou-se neste estudo que o reagente afirmou ter contato com cães e residia em um bairro na periferia.

Estes dois sorovares, Australis e Autumnalis, foram identificados em dois casos de leptospirose aguda humana no município de Pelotas (RS ${ }^{28}$, o que demonstra a importância de conhecer os sorovares presentes nas diferentes áreas, pois, a depender do sorovar identificado na região de estudo, medidas de controle e prevenção deverão ser específicas, observando as particularidades da cadeia de transmissão deste agente.

Em relação ao sorovar Wolffi identificado neste estudo, observou-se que um dos reagentes possuía o hábito de tomar banho em locais com água parada (açudes) e com acesso a animais de produção, o que provavelmente proporcionou o contato com o sorovar encontrado, visto que este é relatado principalmente em bovinos, considerados hospedeiros de manutenção ${ }^{29}$.

De acordo com Waitkins ${ }^{4}$, os animais domésticos podem servir como hospedeiros de manutenção da Leptospira spp. adaptadas a suas espécies, como, por exemplo, o cão infectado com o sorovar Canicola. Existem adaptações de determinados sorovares a certas espécies de animais, que se comportam como portadores adaptados que mantêm a bactéria e contribuem para a manutenção do agente em um determinado lugar, mas a associação não é absoluta e a especificidade dessa manutenção não é conhecida ${ }^{2}$.

Ao observar a análise de associação entre as variáveis analisadas e a sorologia não foi identificado nenhum fator de risco. Entretanto, observou-se maior prevalência em indivíduos do sexo masculino, que foi maior na zona rural, pode estar relacionada ao risco ocupacional, já que geralmente as atividades de limpeza urbana são realizadas principalmente por homens. E na zona rural onde residiam os participantes deste estudo, foi observado que a atividade econômica predominante é o cultivo de grãos e o armazenamento destes alimentos pode favorecer a infestação de roedores. Outros estudos de casos com leptospirose também indicam uma maior ocorrência da infecção em pacientes do sexo masculino ${ }^{15,30-34}$.

Em relação ao fornecimento de água, observouse maior prevalêcia nos trabalhadores que não possuíam em suas residências água encanada, observando associação significativa na análise univariada $(p=0,048)$. Constatou-se maior prevalência em trabalhadores que residiam em casas que alagavam durante as chuvas $(12,5 \%)$. Essas duas variáveis estão diretamente relacionadas com a epidemiologia da doença, visto que a água quando não tratada pode veicular diversos patógenos para o homem, inclusive a Leptospira spp., e que a leptospirose está diretamente relacionada com o contato com água contaminada com urina dos roedores e de animais infectados durante as enchentes. De acordo com Waitkins ${ }^{4}$, os homens são hospedeiros acidentais, e tanto o homem, quanto os animais infectam-se de forma direta quando entram em contato com urina do reservatório contaminada, ou indireta por meio do contato com água, solo lamacento ou alimentos contaminados.

Não foi possível identificar neste estudo associação entre as variáveis: presença de roedor, trabalho em áreas de esgoto a céu aberto, valas, galerias e esgotos. Segundo Adler e Moctezuma², a associação com o risco ocupacional é relatada principalmente nos países com atividades de agricultura e pecuária e o risco de infecção mediada por roedores infectados nos países tropicais, onde muitos sorovares podem estar presentes. Nas áreas urbanas, os profissionais mais expostos ao risco de infecção são os limpadores de caixas de água, fossas e valas ${ }^{34}$, enquanto na área rural os que lidam com o gado, como, por exemplo, vaqueiros, veterinários, 
trabalhadores de matadouro, estão mais expostos ao risco de infecção ${ }^{4}$.

Nos países em desenvolvimento, onde a leptospirose ocorre de maneira endêmica e epidêmica, os fatores de risco não estão relacionados apenas ao risco ocupacional ou lazer, mas para a população como um todo. Já nos países onde ocorre aumento da população de forma desordenada com crescente densidade demográfica, o homem é responsável por modificar a área urbana e favorecer a ocorrência das formas endêmicas e epidêmicas da leptospirose ${ }^{35}$.

Alguns fatores como mudanças climáticas, resultante da atividade humana e práticas de construção (como pavimentação, por exemplo) podem favorecer a ocorrência de inundações, o que facilita a dispersão de micro-organismos infecciosos a partir do solo ou de esgotos para as águas superficias ${ }^{36}$. As condições ambientais favorecem a transmissão do agente, possibilitando modificações da biologia da população, comportamento ou ecologia de espiroquetas e seus hospedeiros no local2 ${ }^{27}$.

No Brasil, alguns fatores como êxodo rural e a ocupação desordenada das cidades, principalmente em lugares próximos a córregos e riachos, além da falta de organização das redes de saneamento básico, aliados a grande aglomeração populacional de baixa renda e infestações de roedores propiciam o aumento de casos no meio urbano e periurbano ${ }^{15}$.

Para controlar e prevenir esta enfermidade é necessário que se adotem medidas como educação em saúde, saneamento ambiental, adoção de medidas higiênico-sanitárias e tratamento precoce dos casos detectados, visto que não é possível realizar a eliminação do principal reservatório desse agente ${ }^{37}$.

\section{CONCLUSÃO}

Este foi o primeiro estudo a relatar a presença de anticorpos anti-Leptospira spp. em trabalhadores urbanos e rurais do município de Garanhuns, Pernambuco. Apesar de não terem sido identificados fatores de risco associados à infecção, os resultados deste estudo alertam para a atenção e realização de pesquisas em áreas de baixa prevalência ou até mesmo áreas silenciosas para leptospirose, pois desta forma medidas de controle e prevenção poderão ser implementadas com o intuito de garantir a saúde da população exposta.

\section{AGRADECIMENTO}

À Fundação de Amparo à Ciência e Tecnologia do Estado de Pernambuco - FACEPE, pela concessão da bolsa.

\section{REFERÊNCIAS}

1. Horsch F. Leptospirose. In: Beer J. Doenças infecciosas em animais domésticos. São Paulo: Roca; 1988. p.305-24.

2. Adler B, Moctezuma ALP. Leptospira and leptospirosis. Vet Microbiol. 2010;140:287-96.

3. Levett PN. Leptospirosis. Clin Microbiol Rev. 2001;14(2):296-326.

4. Waitkins SA. Leptospirosis as an occupational disease. Br J Ind Med. 1986;43:721-5.

5. Sakhaee E, Pour GRA. Detection of leptospiral antibodies by microscopic agglutination test in north-east of Iran. Asian Pac J Trop Biomed. 2011;1(3):227-9.

6. Sergio ADM, Figueroa EG, Saadia VGM, Elizabeth SH, Beatriz RS, Victor MAA, et al. Leptospirosis prevalence in patients with initial diagnosis of dengue. J Trop Med. 2012;1-5.

7. Romero MH, Astudillo M, Sánchez JÁ, González LM, Varela N. Anticuerpos contra Leptospira sp. en primates neotropicales y trabajadores de un zoológico colombiano. Rev. Salud Publica. 2011;13(5):814-23.

8. Pereira MM, Andrade J. Human leptospirosis in a slum area in the city of Rio de Janeiro, Brazil - A serological and epidemiological study. Mem Inst Oswaldo Cruz. 1990;85 (1): 47-52.

9. Almeida LP, Martins LFS, Brod CS, Germano PML. Levantamento soroepidemiológico de leptospirose em trabalhadores do serviço de saneamento ambiental em localidade urbana na região Sul do Brasil. Rev Saude Publica. 1994;1(28):76-81.

10. Gonçalves DD, Teles PS, Reis CR, Lopes FMR, Freira RL, Navarro IT, et al. Seroepidemiology and occupational and environmental variables for leptospirosis, brucellosis and toxoplasmosis in slaughterhouse workers in the Paraná state, Brazil. Rev Inst Med Trop. 2006;48 (2):135-40.

11. Aguiar DM, Cavalcante GT, Camargo LMA, Labruna MB, Vasconcellos AS, Souza GO, et al. Anti-Leptospira spp. and anti-Brucella spp. antibodies in humans from rural area of Monte Negro municipality, state of Rondônia, Brazilian western Amazon. Braz J Microbiol. 2007;38:93-6.

12. Langoni H, Souza LC, Silva AV, Cunha ELP, Silva RC. Epidemiological aspects in leptospirosis. Research of antiLeptospira spp. antibodies, isolation and biomolecular research in bovines, rodents and workers in rural properties from Botucatu, SP, Brazil. Braz J Vet Res Anim Sci. 2008;45(3):190-9.

13. Langoni, H, Hage SSE, Peruca LCB, Lucheis SB, Deffune E. Aglutininas anti-Leptospiras em doadores de sangue. Vet Zoot. 2010;17(1):79-84.

14. Gonçalves DD, Benitez A, Lopes-Mori FMR, Alves LA, Freire RL, Navarro IT, et al. Zoonoses in humans from small rural properties in Jataizinho, Parana, Brazil. Braz J Microbiol. 2013;44(1):125-31. 
15. Vasconcelos CH, Fonseca FR, Lise MLZ, Arsky MLNS. Fatores ambientais e socioeconômicos relacionados à distribuição de casos de leptospirose no Estado de Pernambuco, Brasil, 20012009. Cad Saude Colet. 2012;20(1):49-56.

16. Thrusfield, M. Epidemiologia Veterinária. $2^{\mathrm{a}}$ ed. São Paulo: Roca; 2004. p.556.

17. Brasil. Ministério da Saúde. Resolução CNS no 466, de 12 de dezembro de 2012. Incorpora, sob a ótica do indivíduo e das coletividades, referenciais da bioética, tais como, autonomia, não maleficência, beneficência, justiça e equidade, dentre outros, e visa a assegurar os direitos e deveres que dizem respeito aos participantes da pesquisa, à comunidade científica e ao Estado. Diário Oficial [da] República Federativa do Brasil. Brasília, DF, 13 ago. 2013. Seção 1, p.59. Disponível em: [http://conselho. saude.gov.br/resolucoes/2012/Reso466.pdf]. Acesso em: 17 Nov 2013.

18. Ministério da Saúde. Guia de Vigilância Epidemiológica. Série A. Normas e Manuais Técnicos. $7^{\mathrm{a}}$ ed. Brasília: Ministério da saúde; 2009.

19. Brasil. Fundação Nacional de Saúde. Manual de leptospirose. $2^{\mathrm{a}}$ ed. Brasília: Ministério da Saúde; 1995.

20. Aguiar DM, Cavalcante GT, Vasconcelos AS, Souza GO, Labruna MB, Camargo LMA, et al. Anticorpos anti-Leptospira spp. em ovinos do município de Monte Negro, Estado de Rondônia. Arq Inst Biol. 2010;77 (3):529-32.

21. Salaberry SRS, Castro V, Nassar AFC, Castro JR, Guimarães EC, Lima-Ribeiro MC. Seroprevalence and risk factors of antibodies against Leptospira spp. in ovines from Uberlândia municipality, Minas Gerais State, Brazil. Braz J Microbiol. 2011;42:1427-33.

22. Aguiar DM, Cavalcante GT, Marvulo MFV, Silva JCR, Pinter A, Vasconcelos AS, et al. Fatores de risco associados à ocorrência de anticorpos anti-Leptospira spp. em cães do município de Monte Negro, Rondônia, Amazônia Ocidental Brasileira. Arq Bras Med Vet Zootec. 2007; 59(1):70-6.

23. Batista CSA, Alves CJ, Azevedo SS, Vasconcelos AS, Morais ZM, Clementino IJ, et al. Soroprevalência e fatores de risco para a leptospirose em cães de Campina Grande, Paraíba. Arq Bras Med Vet Zootec. 2005;57:179-85.

24. Ratnam S, Sundararaj T, Subramanian S. Serological evidence of leptospirosis in a human population following an outbreak of the disease in cattle. Trans R Soc Trop Med Hyg. 1983;77(1):94-8.
25. Silva EF, Brod CS, Cerqueira GM, Bourscheidt D, Seyffert N, Queiroz A, et al. Isolation of Leptospira noguchii from sheep. Vet Microbiol 2007;121:144-9.

26. Faine S, Adler B, Bolin C, Perolat P. Leptospira and leptospirosis. CRC Press, 2th. ed. MedSci, Melbourne, 1999.

27. Bharti AR. Leptospirosis: a zoonotic disease of global importance. The Lancet. 2003; 3:757-71.

28. Silva EF, Cerqueira GM, Seyffert N, Seixas FK, Hartwig, Athanazio DA, et al. Leptospira noguchii and human and animal Leptospirosis, Southern Brazil. Emerg Infect Dis. 2009;15(4):621-3.

29. Langoni H, Meireles LR, Gotschalk S, Cabral KG, Silva AV. Perfil sorológico da leptospirose bovina em regiões do Estado de São Paulo. Arq Inst Biol 2000; 67; (1): 37- 41.

30. Andrade J, Brandão, AP. Contribuição ao conhecimento da epidemiologia da Leptospirose humana, com especial referência ao Grande Rio, Brasil, no período de 1970 a 1982. Mem Inst Oswaldo Cruz. 1987;82 (1): 91-100.

31. Costa E, Costa YA, Lopes AA, Sacramento E, Bina JC. Formas graves de leptospirose: aspectos clínicos, demográficos e ambientais. Rev Soc Bras Med Trop. 2001;34(3):261-7.

32. Figueiredo CM, Mourão AC, Oliveira MAA, Alves WR, Ooteman $\mathrm{MC}$, Chamone, et al. Leptospirose humana no município de Belo Horizonte, Minas Gerais, Brasil: uma abordagem geográfica. Rev Soc Bras Med Trop. 2001;34(4):331-8.

33. Soares TSM, Oliveira Latorre MRD, Laporta GZ, Buzzar MR. Análise espacial e sazonal da leptospirose no município de São Paulo, SP, 1998 a 2006. Rev Saude Publica. 2010;44 (2):283-91.

34. Jesus M S, Silva LA, Lima K M S, Fernandes OCC. Cases distribution of leptospirosis in city of Manaus, state of Amazonas, Brazil, 2000-2010. Rev Soc Bras Med Trop. 2012;45(6):713-6.

35. Ávila-Pires FD. Leptospirose e enchentes: uma falsa correlação? Rev Patol Trop. 2006;35(3):199-204.

36. Plank R, Dean D. Overview of the epidemiology, microbiology, and pathogenesis of Leptospira spp. in humans. Microbes Infect. 2000;2:1265-76.

37. Oliveira DSC, Guimarães MJB, Medeiros Z. Modelo produtivo para leptospirose. Rev Patol Trop. 2009;38(1):17-26. 